The Journal of

\title{
Comparative Neurology and Psychology
}

\begin{tabular}{lll}
\hline \hline Volume XVI & JULY, ig06 & Number 4 \\
\hline \hline
\end{tabular}

THE CRANIAL NERVES OF TRITON TENIATUS.

BY

\author{
G. E. COGHILL.
}

(Contribution from the Laboratory of Pacific Unsven sity.)

The studies which have led up to the results which are presented in this paper were undertaken for the purpose of comparing the cranial nerves of Triton with those of Amblystoma, which I have already described ('02), and with a view to examining the position which DR ÜNER ('Or) has taken with reference to certain nerves of the Urodela. Rather than make the comparison with Amblystoma point by point throughout the cranial nervous system, I have introduced only those features which seem to me of morphological significance. In the case of the eye-muscle nerves I have gone into greater detail because $D_{R}$ ÜNER has not included these nerves in his descriptions, which, with the possible exception of his "N. cutaneus retrocurrens IX," must be accepted as accurate so far as general topography is concerned. It is only with reference to the components of certain of the nerves that my observations conflict with his.

The heads of Triton tæniatus upon which my observations have been made were given to me by Professor TH. BoverI, during a brief period in which I enjoyed the hospitality of his laboratory in Würzburg, and I would here express my keen appreciation of the courtesy which he extended to me at that time.

The heads studied were of adults. They were treated with Flemming's stronger chromic-acetic-osmic solution till decalcified. They were cut into serial sections in the three conventional planes. Those of the transverse and sagittal planes were most useful. Although the transverse series are better for the study of the peripheral distribution of the nerves, the sagittal series are indispensable for the study of the roots and ganglia, especially of the ninth 
and tenth nerves. The sections were stained in WeIGERT's hæmatoxylin after mordanting with one-half saturate solution copper acetate.

\section{THE OLFACTORY NERVE.}

My studies of the description of the olfactory nerve of Triton by BuRckHARDT ('9I) led me to expect a sharp division of the root ot this nerve into two fascicles. My serial sections have disappointed me, however, in this, for I find the two divisions of the nerve quite as obscure in their relations in Triton as they are in Amblystoma.

In several of my series of sections of Triton tæniatus it is impossible for me to follow that division of the olfactory nerve which innervates JACOBSON's organ to its destination in the olfactory glomeruli and distinguish it sharply from the remainder of the olfactory nerve; but in two of my series it is clear that the branch of the nerve which arises in JAcoBson's organ forms the most ventral portion of the olfactory nerve and enters the brain further caudad than the rest of the nerve, and in one case it forms a distinct fasciculus of fibers which is more separated from the rest of the nerve in its proximal part than it is farther out.

It would seem, therefore, that Triton and Amblystoma are essentially alike in respect to the arrangement and distribution of the olfactory nerve.

THE EYE-MUSCLE NERVES.

I. N. Oculomotorius.-In its ultimate distribution the oculomotorius of Triton is exactly as in Amblystoma: a r. superior innervates $\mathrm{m}$. rectus superior and a $r$. inferior innervates $\mathrm{m}$. rectus internus, $\mathrm{m}$. rectus inferior, and $\mathrm{m}$. obliquus inferior. In its position relative to other parts, however, the nerve of Triton is peculiar in this respect, that the $r$. superior passes ventrally of the r. ophthalmicus profundus V, while in Amblystoma it passes on the dorsal side of this nerve. This is true in every case excepting one. In this exception the $r$. superior divides upon leaving its foramen. The more ventral division holds the position which the entire nerve regularly takes, while the more dorsal division passes dorsad on the mesial side of the $r$. ophthalmicus profundus 
and enters the $\mathrm{m}$. rectus superior. But in this case, which occurs only on the one side of this specimen, the r. ophthalmicus profundus penetrates the $\mathrm{m}$. rectus superior, whereas it usually passes dorsal of this muscle. This peculiarity of the ophthalmicus in this case no doubt explains the exceptional behavior of the $r$. superior III.

The $r$. inferior is less constant than the r. superior in its position relative to the muscles. It is quite as variable in this respect in Triton as in Amblystoma. In Triton the nerve usually passes caudal or ventral of muscle rectus inferior to arrive at the other two muscles. Frequently, however, the $r$. inferior is penetrated by the proximal portion of the $\mathrm{m}$. rectus inferior and rectus internus.

As compared with the third nerve of Amblystoma, that of Triton requires special notice, also, with reference to the distribution of nerve cells upon it. The occurrence of these ganglion cells can not be adequately treated, however, without first considering two other important relations of the oculomotor nerve of Triton, viz: the branch of the oculomotor to the interior of the eye, and the anastomosis of the r. inferior III with a branch of the r. ophthalmicus profundus $V$.

The oculomotor branch to the interior of the eye comes off the main nerve in or near its foramen. It follows the general direction of the optic nerve and is partially enveloped in the posterior border of the connective tissue sheath of the optic nerve. It is a very small nerve and its fibers are only faintly medullated till they reach the eye, where they lose their medullary sheaths entirely. After penetrating the sclera the nerve can be traced a long distance around the posterior border of the choroid. In a close study of three specimens I have found no important variation in these relations.

The anastomosing branch from the profundus usually arises from the main nerve as the latter crosses the oculomotorius. It then turns directly ventrad and joins the $r$. inferior III. In case the $r$. superior III arises farther centrally than usual, the communicating nerve has been seen to turn a very short distance centrad on the r. superior and enter the r. inferior. In other cases the communicating nerve arises near the Gasserian ganglion. It then becomes a nerve of considerable length, and resembles the corresponding nerve of Amblystoma. 
While this communicating filament between the oculomotorius and the trigeminus appears superficially to be wholly different from anything found in Amblystoma, it actually corresponds to the twig of the profundus which, in Amblystoma, comes in contact with the oculomotorius only after the latter has reached the $\mathrm{m}$. rectus inferior, or which, in some instances, passes independently into the eye under the insertion of the muscle $r$. inferior without coming in touch with the oculomotorius. At a similar point in Triton a division of the $r$. inferior passes into the eye. The real difference, then, between Triton and Amblystoma in this respect is that the inferior ciliary branch of the profundus is more closely fused with the oculomotorius in Triton.

Now the ganglion cells in question occur on both the communicating branch from the profundus and the branch of the oculomotorius to the interior of the eye, and at various points along the main branches of the oculomotorius. They are found upon the r. ophthalmicus profundus at the origin of the communicating branch, upon the latter between the two main nerves, or on the $\mathrm{r}$. inferior III just after it has received the communicating branch. Of these three positions the last has cells most commonly and in greatest numbers. Only in one case have I found cells on the $r$. superior III. Commonly there is a cluster of cells in comparatively large numbers at or near the point of branching of the $r$. inferior III to form its three terminal rami to the muscles. In one specimen, however, no cells occur in this position on one side, whi e on the other side they are found here in considerable numbers. Cells are found, also, in varying numbers on the distinct rami to the $\mathrm{m}$. rectus inferior, rectus internus, and obliquus inferior. Frequently nerve cells are found embedded in these muscles and in close relation with medullated fibers of the oculomotorius. In these cases, however, I have not been able to demonstrate that these cells give rise to the medullated fibers near them. Occasionally nerve cells are found even in isolated positions between the eye-muscles, but apparently connected more or less distinctly with one of the rami of the oculomotorius.

The occurrence of ganglion cells upon the distinct branch of the oculomotor to the eye is subject to wide variation. In one specimen examined there is a distinct cluster of ganglion cells upon this nerve and a very small connective between it and the main ramus inferior of the oculomotorius. In another instance nerve cells 
occur on a connecting filament between the two nerves. Ordinarily, however, there are no ganglion cells found on this nerve. In all probability the cells which occur here belong to the few fibers which in those instances connect the two divisions of the third nerve, and do not contribute to the essential composition of the nerve to the eye.

The most natural interpretation of these nerve cells is that they belong to the sympathetic system, and that they represent the ciliary ganglion. But it is very improbable that many of them have any connection with the ciliary nerves, for, as noted above, they are frequently found isolated from the main nerves, or embedded singly or in small groups in the muscles, or even on the nerve to the rectus internus, from which nerve there is no visible connection with the eye. If, then, they belong to the sympathetic system they must be vasomotor cells. But that there should be such an abundance of vasomotor cells in this region in Triton is exceedingly improbable.

If these cells are not sympathetic cells, it remains only to interpret them as muscle-sensory cells. This is, perhaps, a hazardous suggestion, for it would necessitate the presence of afferent fibers in the oculomotor root, which ranks with the ventral spinal roots as purely motor. But in my paper on Amblystoma I have described a ganglion on the root of the first spinal nerve which has no dorsal root, and, so far as I have been able to determine, it has no fibers which reach the skin. I have considered this latter as a vestigial spinal ganglion, since it does not occur in all specimens. Yet there is no proof that it is functionless. In $T$. tæniatus, on the other hand, nerve cells occur on the oculomotorius of every specimen which has come under my observation. They are much more numerous, also, than similar cells are on the oculomotorius of larval Amblystoma, and since they are constant in occurrence they must be of physiological significance.

But whatever the significance of these cells may be, it is noteworthy that, provided the muscle-sensory fibers of these amphibians are medullated, the $\mathrm{mm}$. rectus internus and obliquus inferior of Amblystoma, and in some instances the $\mathrm{mm}$. recti superior and inferior also, are completely cut off from sensory innervation unless there are afferent fibers in the oculomotor root. The same is true of the mm. rectus internus and obliquus inferior in some specimens of Triton. 
252 Fournal of Comparative Neurology and Psychology.

However, that the nerve cells upon the oculomotorius of Triton and Amblystoma may be the source of sensory innervation of the eye-muscles is merely a suggestion. Further work which I have in progress may contribute something more positive upon the question.

2. N. Trocblearis.-The proximal, intracranial part of the trochlearis is pressed down very closely upon the surface of the brain, underneath or in the meninges, and is, for this reason, so obscure that it might easily be overlooked in good dissections. It passes out of the cranium either as a single nerve or in two divisions. The latter condition, however, is probably rare, and when it does occur the two divisions of the nerve fuse again before they reach the $\mathrm{m}$. obliquus superior, which the trochlearis innervates.

As in Amblystoma, the trochlearis always comes in close relation with a branch of the ophthalmicus profundus. While it is impossible to demonstrate any profundus fibers passing into the trochlearis at this point, it is impossible also to assert that there is not such an interchange of fibers. If the $m$. obliquus superior has any sensory innervation this connection of the trochlearis would seem to be the only possible course for the afferent fibers to enter the profundus. In comparing this trochlearis-profundus connection with the oculomotorius-profundus connections, it is interesting to note that there have been no nerve cells found upon the trochlearis.

3. N. Abducens.--This nerve innervates the usual muscles, rectus externus and retractor bulbi. That either of these muscles ever receives any motor innervation from the fifth nerve is made extremely improbable by the fact that in some instances the sixth nerve does not touch the fifth at any point. In other cases, however, the sixth mingles with the ganglion cells of the profundus ganglion so that the relation between the two nerves is very obscure. In still other instances, a ganglionated branch of the profundus, just beyond the ganglion, is observed to join the sixth nerve. In one case of this kind, however, there seems to be a passage of fibers from the sixth into the third nerve, and in this particular instance the usual connective between the profundus and the oculomotorius is wanting. This connective between the sixth and fifth may, therefore, be only the commissure to the third nerve. Yet in other cases, when no such connection with the third nerve can be made out, there are ganglion cells on the sixth 
nerve. I see no reason why these may not be muscle-sensory cells which have passed out from the profundus ganglion to the motor nerve. Yet such cells are found upon the sixth nerve when it has no connection with the ganglion or any branch of the fifth.

THE FIFTH AND SEVENTH NERVES.

There is no noteworthy difference, so far as my observations go, between Amblystoma and Triton with respect to the roots and ganglia of the fifth and seventh nerves. With respect to certain of the rami, however, there are some peculiarities which demand notice.

I. The Ramus Opbtbalmicus Profundus V.-The most conspicuous peculiarity of this nerve is that it passes on the dorsal side of the $\mathrm{m}$. rectus superior and the $r$. superior III. It passes ventrally of these structures in Amblystoma.

In the arrangement of the smaller branches of this nerve there are peculiarities which are apparently due to the general topography of the head, but they do not affect the ultimate distribution, which can not be distinguished from that of Amblystoma. The peculiarity of the inferior ciliary nerve has been noticed in connection with the $r$. inferior III. The superior ciliary, as in Amblystoma, in some cases comes in close relation with the $r$. superior III, and penetrates the muscle rectus superior, while in other cases it comes in touch with neither this nerve nor the muscle, excepting under the insertion of the latter, where it penetrates the sclera to the interior of the eye.

The terminal branches of the profundus differ from those of Amblystoma only in unimportant details which are probably incident to skeletal peculiarities. The relation between the ventral terminal branch and the palatinus VII is obscure unless the sections are cut in exactly the right plane, and even then it requires close study to determine the exact conditions. It is clear enough that a large bundle of profundus fibers passes through the palatine ganglion and unites with fibers from $r$. palatinus VII. The resulting nerve continues cephalad on the mesial side of the internal nares. Some of its fibers seem to terminate in the ventral portion of the nasal epithelium and the nerve lies for the most part within the nasal chamber and is intimately associated with branches of the olfactory nerve at different points. Several small branches 
254 Fournal of Comparative Neurology and Psychology.

pass ventrad through foramina in the floor of the nasal chamber, and branch out to the oral epithelium. Some of these twigs reach the vicinity of the gums. Whether they connect with the teeth or with taste buds that occur very near them is not clear. The lateral division of the ventral ophthalmic branch is much more difficult to trace. Nevertheless my preparations have enabled me to determine conclusively that the branch of the palatine which passes laterad around the caudal border of the internal nares is accompanied by profundus fibers. This relation is not clear in all cases, but enough cases are clear to convince me that the apparent exceptions are due to the complexity of the anastomosis and the direction of the plane of section. In at least two of my specimens the lateral branch of the palatine connects, also, with a division of the lateral terminal branch of the profundus. In these particular cases, however, it is impossible to trace any fibers from the ventral terminal branch of the profundus into the lateral palatine branch.

With these exceptions Triton and Amblystoma seem to agree exactly with respect to the relations of the r. palatinus VII and $r$. ophthalmicus profundus $V$. A peculiar relation of the $r$. buccalis VII to these nerves in Triton will be described in connection with the buccal nerve.

2. The Truncus Infraorbitalis. - The only feature of this division of the trigeminus which demands special notice is the relation of the so-called $r$. maxillaris V and the $r$. buccalis VII to one another and to the r. palatinus VII.

The term maxillaris, as applied to the general cutaneous branch of the trigeminus which passes beneath the eye in the upper jaw of Urodeles, is used here with the qualification that it is not to be considered the homologue of the r. maxillaris superior of Anura. My reasons for this interpretation have been given in my earlier papers ('OI, '(22), and some further consideration of it will be offered in the general discussion which follows the descriptive part of this communication.

These nerves, in their proximal region, are best studied in sections cut parallel to the sagittal plane. In some instances the buccalis is purely lateralis, and the maxillaris is purely general cutaneous as far as their point of flexure cephalad. Here the nerves cross each other in such an intricate manner that it has been impossible for me to assure myself that beyond this point 
either nerve is made up of one component exclusively. But it is certain that if the $r$. buccalis receives general cutaneous fibers at any point, the number of such fibers is exceedingly small. The r. buccalis is always composed of uniformly large fibers, which are characteristic of the acustico-lateralis system. Also, if lateralis fibers occur in the r. maxillaris, they are very few and of irregular occurrence.

These two nerves do not differ in any important feature from the corresponding nerves of Amblystoma till they reach the level of the cephalic border of the eye. Here, or in some cases considerably farther cephalad, the $r$. maxillaris passes through the maxillary bone and passes outward and downward into the upper lip; while the $r$. buccalis, ordinarily lying farther mesad, sends a slender filament mesad, which penetrates the cartilaginous wall of the nasal capsule and, passing around the caudal border of the nasal epithelium and the internal nares, joins the mesial branch of the ophthalmico-palatine nerve. This communicating nerve is sometimes fused with the lateral terminal branch of the palatine, but in some instances it is wholly separated from this nerve and from the palatine ganglion also, and joins the nerve from this ganglion only after passing a considerable distance cephalad mesially of the internal nares.

On one side of one of my specimens the nerve in question arises from the r. maxillaris. Yet, since in this one exception, because of the intimate relation of the $r$. maxillaris with the $r$. buccalis, it is possible that lateralis fibers are carried out with the r. maxillaris, the natural inference is that this communicating nerve belongs to the acustico-lateralis system. This interpretation is further borne out by the fact that the terminal twig of the palatine nerve, with which this nerve unites, after traversing the whole length of the nasal chamber ventrally of the nasal epithelium, passes through the cephalic wall of the capsule and through the premaxillary bone and terminates in the lateral line organs at the very tip of the snout.

Just outside the foramen in the premaxillary bone this terminal filament of the palatine crosses a branch of the mesial terminal ramus of the ophthalmicus profundus which carries general cutaneous fibers from the adjacent region. Since the latter nerve does not at any point come into close relation with the acusticolateralis system of fibers, and since no lateralis fibers from any 
$25^{6}$ Fournal of Comparative Neurology and Psychology.

other source can be traced into the vicinity of the lateral line organs in question, the communicating nerve from the r. buccalis to the palatine must be the only path by which lateralis fibers can reach these organs. This is strong indirect evidence to show that the communicating nerve carries lateralis fibers, but it does not prove that it is exclusively lateralis in composition. The possibility remains that it is composed partly of general cutaneous fibers. However, it would not seem reasonable for general cutaneous fibers to travel this round-about road to a region which is already, by most direct route, profusely supplied with general cutaneous innervation by the mesial terminal ramus of the ophthalmicus profundus. Both indirect and direct evidence, therefore, is very strong to prove that the communicating nerve between the $\mathrm{r}$. buccalis and the palatine nerve belongs to the acustico-lateralis system.

3. The Communis Component of the Facial.-Beyond the descriptions of the terminal branches of the $r$. palatinus, already given, there is nothing particularly noteworthy regarding this nerve in Triton as compared with Amblystoma. It arises from the cephalic portion of the geniculate ganglion, from which the fibers of the $r$. alveolaris pass directly laterad with the hyomandibular trunk. The nerve called palatinus caudalis in Amblystoma occurs also in Triton. It varies considerably in its point of origin, sometimes coming out of the ganglion almost at the base of the r. palatinus, sometimes about half way through the facial canal leaving the hyomandibular trunk through a special foramen. In one case it seemed to be represented by fibers which leave the communis component of the hyomandibular just outside of the facial canal. My preparations show conclusively that this is a communis nerve from the geniculate ganglion, and that it anastomoses with a nerve of about the same dimensions from the glossopharyngeus. The fibers of the two nerves pass cephalad together from the point of anastomosis. They can be traced cephalad in the roof of the mouth as far as the central level of the eye. This is the true JACOBson's anastomosis, and should not be confused with the other connective between the vagus and facial.

There is one peculiarity of the $r$. alveolaris: It receives no fibers from the glossopharyngeus, such as were described in Amblystoma. There is a large branch of constant occurrence which arises near the angle of the jaw and turns mesad to the epithelium between the hyoid and mandibular arch. 
THE NINTH AND TENTH NERVES.

I. The Roots and Ganglia.-As to general morphology DRÜNER has correctly described the ganglia of the glossopharyngeus and vagus and the nerve trunks which arise from them. The composition of the roots and trunks of these nerves, however, demands some further definition.

The roots which correspond to my second, third and fourth vagus roots of Amblystoma are variable in their arrangement relative to each other, but always exhibit more compactness than in larval Amblystoma-a peculiarity due, no doubt, to the adult condition and of no morphological significance. But in my specimens which show the origin of the roots most clearly one fact of importance is clear: There are no motor axones in the general cutaneous root of the vagus. This can not be stated as a universal condition, but it is certainly true in some indviduals, while no positive exceptions have come under my observation. This would appear at first thought to be essentially different from the condition described for Amblystoma ('o2, Plate I, X 3), but in all probability the motor axones figured in my third vagus root of Amblystoma belong to the fourth root, as was stated in my original description ('O2, p. 234). This being true, the general cutaneous root of Triton and Amblystoma alike would be unaccompanied by motor axones.

In composition, the nerves which arise from the IX-X ganglionic complex of Triton correspond exactly with those of Amblystoma. This can be positively stated for all but the motor components, which can be differentiated from the sensory neurones within the ganglia only in very young specimens. As these were not accessible to me I have been unable to follow the motor axones through the ganglia of Triton successfully, as I have done in Amblystoma. But the exact resemblance of the two types in respect. to the other features of these nerves would seem to justify one in assuming that the motor components of the two forms, also, would follow the same laws of distribution.

2. The Truncus Glossopbaryngeus.--There are no general cutaneous fibers in the root of the glossopharyngeus, but this component enters the trunk of the nerve from the ganglion of the vagus. These fibers usually enter the nerve within the ganglion and are hard to identify with certainty. In one case, however, 
$25^{8}$ Fournal of Comparative Neurology and Psychology.

I find this component leaving the vagus ganglion as a distinct nerve and passing out a considerable distance before it unites with the glossopharyngeus just before the latter gives off the $\mathrm{r}$. communicans $\mathrm{X}$ ad VII. The fibers of this nerve, within the ganglion, have all the appearance of sensory fibers; and since, as stated above, there appear to be no motor fibers in the general cutaneous root of the vagus, one seems to be justified in interpreting this component of the glossopharyngeus as sensory. Furthermore this is the only interpretation which will account for the fibers of this nerve which have a general cutaneous distribution. On any other supposition one would have to assume that communis fibers have a general distribution to the skin without relation to sense buds-a supposition which would scarcely be warranted by our present knowledge of nerve components.

The general cutaneous component of the glossopharyngeus in Amblystoma is distributed to the skin of the first external gill and over the base of this structure, and through the r. communicans to the $\mathrm{r}$. jugularis VII. In the absence of the external gill in the adult Triton, a general cutaneous branch of this nerve is distributed to a corresponding region and, as explained below, there is good proof that the remainder of the general cutaneous component of the glossopharyngeus enters the r. communicans $\mathrm{X}$ ad VII.

3. The Ramus Communicans $X$ ad VII.--It is impossible for me to trace the axones of this nerve with perfect certainty to their origin in the nerve roots and thus to determine its composition beyond dispute as I have done in the case of Amblystoma; but in the case cited above, in which the vagus component of the glossopharyngeal trunk joins the latter just before the $\mathrm{r}$. communicans is given off, there is a space of only ten sections ten micra thick in which it is impossible to distinguish the vagus component or the r. communicans clearly from the rest of the nerve. This indistinctness is due to the tortuous course of the nerve at and near this point of flexure ventrad where the r. communicans arises. However, a study of the position which the vagus component takes in the trunk and of the point of origin of the $r$. communicans makes it almost certain that the $r$. communicans is derived, at least in part, from the vagus component.

As the $r$. communicans passes cephalad to join the $r$. jugularis VII, it gives off no fibers to any muscle, but it meets fibers from 
the motor VII component which enter the $\mathrm{m}$. depressor mandibulæ.

After the r. jugularis VII receives the r. communicans it passes around the cephalic to the lateral border of the $\mathrm{m}$. depressor mandibulæ, and gives fibers to this muscle and to the skin. The only possible source for these general cutaneous fibers is the vagus ganglion via r. communicans, since there are no general cutaneous fibers in the roots of the facial nerve.

4. Other Branches of the Glossopharyngeus and Vagus.DRÜNER's descriptions of the other branches of the ninth and tenth nerves are accurate, with the possible exception of his $r$. "N. cutaneous retrocurrens IX." This nerve, he believes, innervates sense organs on the ventral surface of the head. Such a nerve can not be made out with certainty in my preparations, but since the corresponding nerve of Salamandra, according to DR ÜNER, disappears during the metamorphosis, it may tend to disappear in the adult of Triton. However, wherever such a nerve may appear the fact should be emphasized that there are no fibers of the lateral line system in the glossopharyngeus of 'Triton. My preparations are perfectly clear on this point. The "N. cutaneus retrocurrens IX," then, can not be a lateral line nerve, for in my specimens the lateral line organs and nerves are well preserved and stained.

This nerve is deserving of further study, for if it really innervates sense organs it must be a communis nerve, and the presence of taste buds of this system in the skin of Amphibia would be an interesting discovery. Observations which I have begun on larvæ of Triton torosus may contribute something to this subject.

GENERAL DISCUSSION.

I. The Relation of the R. Maxillaris Superior to the R. Palatinus.-The connective between the r. buccalis and the palatine nerve as I have described it above is of interest when compared with the anastomoses between the corresponding nerves of Amphiuma, as described by KingsLeY ('O2). But unfortunately this author has not, in his treatment of this nerve, differentiated the lateral line and cutaneous components, that is to say, the $r$. buccalis and r. maxillaris; although he says the maxillaris superior "equals not only the maxillaris superior but the buccalis as well," 
and that "this nerve is clearly a double one." He identifies various branches of the nerve as "buccalis" divisions, but by their distribution only, and not by their certain origin from the lateralis ganglion. Two of the divisions of the nerve which may be so identified from KingsLey's descriptions are the middle and inner terminal branches, which arise from the main nerve near the level of the cephalic border of the eye and almost immediately anastomose with the rami of the ophthalmicus profundus. The two nerves thus formed pass through foramina in the maxillary bone and innervate organs of the infraorbital line.

Now, in Triton there is a single small nerve which arises in the same locality from the $\mathrm{r}$. buccalis and passes mesad into the nasal capsule. Here it anastomoses with the mesial nerve which arises from the palatine ganglion and which is composed of both profundus V and communis VII fibers. In these relations the nerve differs conspicuously from the anastomoses which KingsLeY describes for the maxillaris superior of Amphiuma. Nevertheless, in both instances the tendency is shown for the buccalis fibers which are destined for the more cephalic organs of the lateral line to fuse with rami of the profundus. This tendency seems to be more pronounced in those forms which have greater ossification in the maxillary region. Indeed, it may be only incident to this skeletal condition, since in larval Amblystoma, in which ossification is very slight in the maxillary region, the buccalis does not anastomose with the ophthalmicus at any point.

But the most important feature of these anastomoses is the fact that, so far as they have been analyzed, they are between the profundus (plus r. palatinus in Triton) and lateralis fibers and not between the profundus and other general cutaneous fibers. Consequently KingsLeY's statement ('O2, p. 302) that "In higher vertebrates this union, or a similar one between maxillaris and lachrymal, is common," can scarcely be correct; for such an interpretation would require that we make a general cutaneous nerve of the sauropsida or mammalia homologous with a lateral line nerve of the ichthyopsida.

It is not clear from his paper that Professor Kingsley would himself adopt such an hypothesis as a sound morphological principle, although he states clearly that these maxillaris divisions in question carry lateral line fibers and offers no evidence to show that they contain trigeminal fibers. 
Another point of interest, also, attaches to this communicating nerve between the buccalis and the palatine nerve in Triton, for KINGSLEY ('O2 a, p. 378 ) describes a very similar connective between the maxillaris superior and the r. palatinus in Ichthyophis. Although in this account, which is brief and only preliminary, Professor KINGSLEY has given nothing to establish the composition of this anastomosis, he considers it homologous with the anastomosis between the $r$. maxillaris superior and the $r$. palatinus of the frog. Yet I can see no reason why this connective in Ichthyophis may not be simply a lateral line nerve like that of Triton.

In his discussion of the taxonomic position of the creilians Professor KingsLeY attaches "a considerable weight . . . to the relation existing between the palatine branch of the seventh and the various branches of the fifth nerves." But the bearing of the evidence to be drawn from this relation, it seems to me, hangs largely upon the morphology of the trigeminal branches themselves. It is my conviction that the nerves which are called maxillaris superior in Anura and in Urodela are not equivalent nerves in the two groups; but that the maxillaris of Urodela is the equivalent of STrong's " $r$. accessorius" of the tadpole, while the $r$. maxillaris superior of Anura is represented in the Urodela by lateral divisions of the ophthalmicus profundus. My reasons for this interpretation have been stated in my earlier papers ('or; '02, p. 260-262), and my study of Triton, with the discovery of the lateral line connective between the $r$. buccalis and the palatine nerve, has confirmed my position on this point. The essential facts concerning the relation of these nerves among themselves may be summarized as follows: The r. accessorius and r. maxillaris of Urodela are alike both in their distribution and in their relation to the $r$. buccalis VII, and do not anastomose with the $r$. palatinus VII; while the r. maxillaris of Anura and certain lateral divisions of the $r$. ophthalmicus profundus of the Urodela are alike in their distribution to the skin and in the anastomoses with the $r$. palatinus VII. And, here, it should be emphasized that the connective between the $r$. buccalis and palatine nerve in Triton is not comparable to the maxillo-palatine anastomosis of Anura for two reasons. In the first place, all the evidence goes to prove that it is a lateral line nerve. In the second place, it passes to the mesial side of the internal nares, so that, even if 
it were a general cutaneous nerve, its distribution would exclude it from being homologized with the maxillopalatine anastomosis of Anura for the latter is distributed to the lateral side of the internal nares. In this connection, also, KINGSLEY's description of the anastomosis between the r. palatinus and profundus of Amphiuma is of special interest; the conspicuous part of the anastomosis passes to the lateral side of the internal nares. In Amblystoma and Triton this lateral nerve from the anastomosis is obscure in its composition, which can be determined only under favorable conditions, while the mesial division is the larger and is clearly composed of trigeminal and facialis fibers. It is my belief that this nerve " $\mathrm{e}$ " of KingsLey in Amphiuma, which is composed of fibers from the r. palatinus and $r$. ophthalmicus profundus, represents the nerve which is formed from the $r$. palatinus and r. maxillaris superior in Anura.

In the light of the more recent work on the cranial nerves of Amphibia I can not understand why the r. maxillaris superior of Anura should be homologized with the nerve which the earlier authors called $r$. maxillaris in Urodela. These authors apparently knew nothing of the nerve which STRONG named $r$. accessorius in anuran larvæ. They found in the adult Anura only the one nerve which could be compared with the r. maxillaris of Urodela and to which they gave the same name. It seems to me unfortunate that this error should be perpetuated in opposition to facts which have become established by more exact methods than were at the command of earlier investigators.

With reference to the comparison of Amphibia with fishes as to the relation existing between the $r$. palatinus VII and the trigeminus, Kingsley ('O2 a, p. 339) cites Pollard's description of a connective between the r. palatinus and maxillaris superior in Polypterus. Now the significance of this connective hangs upon its composition. So far as we know it may be a communis nerve. If it is such, it then has no relation whatever to a general cutaneous connective between the trigeminus and the r. palatinus, for the communis fibers which associate with the $r$. maxillaris in fishes belong to the facialis.

2. Facobson's Anastomosis and R. Communicans $I X-X$ ad $V I I$.--In his paper on Amphiuma KingsLeY uses these two terms as synonymous. NorRIs ('05), also, in his description of certain cranial nerves of Amphiuma applies the term JAcoBson's anas- 
tomosis to the $\mathrm{r}$. communicans IX-X ad VII. It seems necessary, therefore, to emphasize the distinctness of these two structures. Cole ('98) has stated clearly the ground for distinguishing between them. The true JACOBSON's anastomosis belongs to the communis system and is distributed to the oral epithelium; while the $r$. communicans sends fibers to the skin and must be considered as a general cutaneous nerve, at least in the larger part. On the last point DRÜNER differs with me, since he considers this nerve as motor. But whether it be general cutaneous or motor it should not be confused with JACOBSON's anastomosis.

In Amblystoma, it is true, I found communis fibers in the $r$. communicans. But in this case the communis fibers joined the $r$. alveolaris and passed ventrad toward the floor of the mouth, so that their distribution is clearly different from that of the fibers in JACoBson's anastomosis. The two anastomoses between the facialis on one hand and the glossopharyngeus and vagus on the other exist side by side in both Amblystoma and Triton, and a close study of these two structures here convinces me that the $r$. communicans IX-X ad VII is in no way comparable to JAcoBson's anastomosis.

As already mentioned, DRÜNER holds that the $r$. communicans is a motor nerve. I have been unable, however, to find any motor fibers in it, either in Amblystoma or in Triton. The fibers which may appear to go from it to the muscle depressor mandibulæ before the r. communicans reaches the r. jugularis are, in Triton as well as in Amblystoma, clearly derived from the r. jugularis. They pass caudad a variable distance in more or less close relation with the r. communicans. On the other hand, as presented in my description of this nerve, there is convincing evidence that the nerve is general cutaneous. And, being general cutaneous, it belongs to the vagus, for the glossopharyngeus gets its general cutaneous fibers from the vagus root. The term $\mathrm{r}$. communicans IX-X ad VII, or X ad VII is, then, a better expression of the actual relations of the nerve. In Amblystoma I found that it belongs to both the glossopharyngeus and vagus. In Triton, I believe it belongs exclusively to the vagus. 


\section{Fournal of Comparative Neurology and Psychology.}

\section{LITERATURE CITED.}

Burckhardi, Rud., '9i. Unterschungen am Hirn und Geruchsorgan von Triton und Ichthyophis. Zeitschrift f. wissen. Zool., Bd. 52, No. 3 .

Coghild, G. E., 'or. The Rami of the Fifth Nerve in Amphibia. Four. Comp. Neurology, Vol. ir, No. I.

'02. The Cranial Nerves of Amblystoma Tigrinum. Four. Comp. Neurology, Vol. 12, pp. 205-289.

Cole, Frank J., ' 98 . Observations on the Structure and Morphology of the Cranial Nerves and Lateral Line Sense Organs of Fishes; with Special Reference to the Genus Gadus. Trans. Linn. Soc. London, 2 Ser., Vol. 7, Part 5.

DrüNer, L., 'or. Studien zur Anatomie der Zungenbein-, Kiemenbogen- und Kehlkopfmuskeln der Urodelen. I. Theil. Zool. Fahrb. Bd. 15, pp. 435-622.

Kingstey, J. S., 'o2. The Cranial Nerves of Amphiuma. Tufis College Studies, No. 7, pp. 293-321.

'o2 a. The Systematic Position of the Cacilians. Tufts College Studies, No. 7, pp. 323-344.

Norris, H. W., 'o5. The So-called Dorsotrachealis Branch of the Seventh Cranial Nerve in Am. phiuma. Anat. Anz., Bd. 27, pp. 271-272.

Strong, Oriver S., '95. The Cranial Nerves of Amphibia. A Contribution to the Morphology of the Vertebrate Nervous System. Four. Morph. Vol. IO, No. x. 